Jurnal Matematika UNAND

Vol. VII No. 4 Hal. $27-32$

ISSN : 2303-291X

(C)Jurusan Matematika FMIPA UNAND

\title{
MATRIKS FUZZY REGULAR
}

\author{
MURTIA ZAILI, NOVA NOLIZA BAKAR, MONIKA RIANTI HELMI \\ Program Studi Matematika, \\ Fakultas Matematika dan Ilmu Pengetahuan Alam, Universitas Andalas, \\ Kampus UNAND Limau Manis Padang, Indonesia. \\ email : murtiazaili10@gmail.com
}

\begin{abstract}
Abstrak. Matriks fuzzy adalah matriks yang entri-entrinya berada pada selang tutup $[0,1]$. Operasi pada matriks fuzzy berbeda dengan matriks pada umumnya, penjumlahan pada matriks didefinisikan sebagai maksimum dari entri-entri yang bersesuaian dan perkalian pada matriks fuzzy didefinisikan sebagai minimum dari entri-entri pada matriks fuzzy tersebut. Matriks fuzzy A dikatakan regular jika memenuhi persamaan AXA $=\mathrm{A}$, dalam hal ini X dikatakan g-invers dari A dan dilambangkan dengan $A^{-}$. Jika $\mathrm{R}(\mathrm{A})$ $=\mathrm{R}(\mathrm{B})$ atau $\mathrm{C}(\mathrm{A})=\mathrm{C}(\mathrm{B})$ maka $\mathrm{A}$ adalah matriks fuzzy regular jika dan hanya jika $\mathrm{B}$ adalah matriks fuzzy regular.
\end{abstract}

Kata Kunci: Aljabar fuzzy max-min, matriks fuzzy, ruang baris, ruang kolom, idempoten, generalisasi invers, matriks fuzzy regular

$\begin{array}{lll}\text { Diterima } & : & \text { 29 November } 2018 \\ \text { Direvisi } & : & 3 \text { Desember } 2018 \\ \text { Dipublikasikan } & : & \text { 30 Desember } 2018\end{array}$

\section{Pendahuluan}

Matriks fuzzy adalah matriks yang entri-entrinya berada pada selang tutup [0,1]. Semua matriks fuzzy merupakan matriks, akan tetapi untuk sebarang matriks belum tentu merupakan matriks fuzzy. Penjumlahan, perkalian skalar pada matriks fuzzy berbeda dengan matriks pada umumnya. Penjumlahan pada matriks fuzzy didefinisikan sebagai maksimum dari entri-entri yang bersesuaian dan perkalian pada matriks fuzzy didefinisikan sebagai minimun dari entri-entri matriks fuzzy tersebut.

Suatu matriks memiliki invers jika matriks tersebut berukuran $n \times n$ dan determinan matriks tersebut tidak sama dengan 0 , untuk mencari invers dari matriks selain berukuran $n \times n$ digunakan generalisasi invers. Matriks $\mathrm{X}$ dikatakan generalisasi invers (g-invers) dari matriks A jika matriks $\mathrm{X}$ ada sedemikian sehingga AXA $=\mathrm{A}$. Matriks fuzzy yang memiliki g-invers disebut matriks fuzzy regular.Matriks fuzzy A memiliki banyak g-invers, himpunan semuag-invers dari matriks fuzzy A dinotasikan A1.

\section{Aljabar Fuzzy}

Definisi 2.1. [1] Misalkan $F$ suatu himpunan. Sistem matematika $(F,+, \cdot)$ dengan operasi biner "+" dan "." yang didefinisikan pada himpunan F adalah aljabar fuzzy. Jika untuk setiap a, b, $c \in F$, berlaku: 
(1) $a+a=a$ dan $a \cdot a=a$,

(2) $a+b=b+a$ dan $a \cdot b=b \cdot a$,

(3) $a+(b+c)=(a+b)+c$ dan $a \cdot(b \cdot c)=(a \cdot b) \cdot c$,

(4) $a+(a \cdot b)=a$ dan $a \cdot(a+b)=a$,

(5) $a \cdot(b+c)=(a \cdot b)+(a \cdot c)$ dan $a+(b \cdot c)=(a+b) \cdot(a+c)$,

(6) terdapat $0 \in \mathcal{F}$ sehingga $a+0=a$ dan $a \cdot 0=0$,

(7) terdapat $1 \in \mathcal{F}$ sehingga $a+1=1$ dan $a \cdot 1=a$.

Berikut contoh dari aljabar fuzzy. Misalkan himpunan bilangan fuzzy $\mathcal{F}=[0,1]$ dengan operasi $(+, \cdot)$ didefiisikan sebagai: $a+b=\operatorname{maks}\{a, b\}$ dan $a \cdot b=\min \{a, b\}$ untuk semua $a, b \in[0,1]$. Ini diebut aljabar fuzzy max-min. [1]

\section{Matriks Fuzzy}

Definisi 3.1. [1] Misalkan $\mathcal{F}_{m n}$ merupakan himpunan semua matriks berukuran $m \times n$ atas aljabar fuzzy $\mathcal{F}$ dengan $\mathcal{F}=[0,1]$. Apabila $m=n$, maka dapat ditulis $\mathcal{F}_{n}$ dan elemen-elemen dari $\mathcal{F}_{m n}$ merupakan matriks fuzzy.

Definisi 3.2. [3] Matriks $A=\left[a_{i j}\right]$ dikatakan matriks fuzzy jika $a_{i j} \in \mathcal{F}=[0,1]$.

Definisi 3.3. [1] Misalkan $A=\left[a_{i j}\right]$ dan $B=\left[b_{i j}\right]$ adalah matriks-matriks fuzzy berukuran $m \times n$, maka penjumlahan dari $A, B$ didefinisikan sebagai berikut:

$$
A+B=\left[a_{i j}+b_{i j}\right]=\left[\operatorname{maks}\left\{a_{i j}, b_{i j}\right\}\right] .
$$

Definisi 3.4. [1] Misalkan $A=\left[a_{i j}\right]$ adalah matriks fuzzy berukuran $m \times p$ dan $B=$ $\left[b_{i j}\right]$ adalah matriks fuzzy berukuran $p \times n$, maka perkalian dari $A, B$ didefinisikan sebagai berikut:

$$
A \cdot B=\left[a_{i j} \cdot b_{i j}\right]=\left[\sum_{k=1}^{p} a_{i k} \cdot b_{k j}\right]=\left[\operatorname{mak} s_{k}\left\{\min \left\{a_{i k}, b_{k j}\right\}\right\}\right] .
$$

Definisi 3.5. [1] Misalkan $A=\left[a_{i j}\right]$ adalah matriks fuzzy berukuran $m \times n, k \in$ $\mathcal{F}=[0,1]$, maka perkalian dari $k, A$ didefinisikan sebagai berikut:

$$
k \cdot A=\left[k \cdot a_{i j}\right]=\left[\min \left\{k, a_{i j}\right\}\right] .
$$

Definisi 3.6. [1] Untuk matriks $A \in \mathcal{F}_{m n}$, matriks $A$ dikatakan idempoten jika $A^{2}=A$.

Definisi 3.7. [1] Untuk $A \in \mathcal{F}_{m n}$, transpos dari $A$ diperoleh dengan mempertukarkan baris-baris ke kolom-kolom dari $A$, dan dilambangkan dengan $A^{T}$.

Teorema 3.8. [1] Misalkan $A \in \mathcal{F}_{m n}, B \in \mathcal{F}_{n p}$ maka berlaku:

1. $\left[A^{T}\right]^{T}=A$.

2. $[A B]^{T}=B^{T} A^{T}$.

Teorema 3.9. [1] Misalkan $A \in \mathcal{F}_{m n}, B \in \mathcal{F}_{n p}, C \in \mathcal{F}_{p q}$, maka berlaku:

$$
(A B) C=A(B C) \text {. }
$$




\subsection{Ruang Baris dan Ruang Kolom Matriks Fuzzy}

Definisi 3.10. [1] Misalkan $V_{n}$ merupakan himpunan n-tuples $\left(x_{1}, x_{2}, \cdots, x_{n}\right)$ atas aljabar fuzzy $\mathcal{F}=[0,1]$. Elemen-elemen dari $V_{n}$ disebut vektor fuzzy berdimensi $n$. Operasi penjumlahan dan perkalian pada $V_{n}$ didefinisikan sebagai berikut:

Untuk setiap $x=\left(x_{1}, x_{2}, \cdots, x_{n}\right), y=\left(y_{1}, y_{2}, \cdots, y_{n}\right) \in V_{n}$, dan $a \in \mathcal{F}=[0,1]$, maka:

$x+y=\left(\operatorname{maks}\left\{x_{1}, y_{1}\right\}, \operatorname{maks}\left\{x_{2}, y_{2}\right\}, \cdots, \operatorname{maks}\left\{x_{n}, y_{n}\right\}\right)$, dan $a x=\left(\min \left\{a, x_{1}\right\}, \min \left\{a, x_{2}\right\}, \cdots, \min \left\{a, x_{n}\right\}\right)$.

Sistem $V_{n}$ dengan operasi penjumlahan dan perkalian skalar fuzzy disebut ruang vektor fuzzy atau ruang vektor atas aljabar fuzzy $\mathcal{F}=[0,1]$.

Definisi 3.11. [1] Subruang dari $V_{n}$ adalah sub himpunan $W$ dari $V_{n}$ sedemikian sehingga $\boldsymbol{O} \in W$ dan untuk $x, y \in W$ maka $x+y \in W$.

Definisi 3.12. [1] Ruang baris dari matriks $A$ yang berukuran $m \times n$, ditulis $R(A)$ adalah subruang dari $V_{n}$ yang dibangun oleh baris-baris dari $A$. Ruang kolom dari matriks $A$ yang berukuran $m \times n$, ditulis $C(A)$ adalah subruang dari $V_{n}$ yang dibangun oleh kolom-kolom dari $A$, dan $C(A)=R\left(A^{T}\right)$.

Teorema 3.13. [1] Misalkan $A, B \in \mathcal{F}_{m n}$, maka berlaku:

(1) $R(B) \subseteq R(A)$ jika dan hanya jika $B=X A$ untuk suatu $X \in \mathcal{F}_{m}$.

(2) $C(B) \subseteq C(A)$ jika dan hanya jika $B=A Y$ untuk suatu $Y \in \mathcal{F}_{n}$.

Definisi 3.14. Misalkan $A, B \in \mathcal{F}_{m n}$, maka:

1. $R(B)=R(A)$ artinya $R(B) \subseteq R(A)$ dan $R(A) \subseteq R(B)$.

2. $C(B)=C(A)$ artinya $C(B) \subseteq C(A)$ dan $C(A) \subseteq C(B)$.

\section{2. g-invers}

$A \in \mathcal{F}_{m n}$ dikatakan regular jika ada $X \in \mathcal{F}_{n m}$ sehingga $A X A=A$. Dalam hal ini, $\mathrm{X}$ disebut g-invers dari A dan dilambangkan dengan $A^{-}$.

\section{Matriks Fuzzy Regular}

Definisi 4.1. [1] Misalkan $A \in \mathcal{F}_{m n}$, matriks $A$ adalah regular jika dan hanya jika A mempunyai g-invers. Jika A adalah regular, maka g-invers dari A dilambangkan sebagai $A^{-}$, dan $A\{1\}$ adalah himpunan dari semua g-invers dari $A$ yang memenuhi $A A^{-} A=A$.

Lema 4.2. [1] Misalkan $A, B \in \mathcal{F}_{m n}$, jika $A$ adalah matriks fuzzy regular, maka akan berlaku:

(1) $R(B) \subseteq R(A)$ jika dan hanya jika $B=B A^{-} A$ untuk suatu $A^{-} \in A\{1\}$.

(2) $C(B) \subseteq C(A)$ jika dan hanya jika $B=A A^{-} B$ untuk suatu $A^{-} \in A\{1\}$.

Bukti. 
(a) Misalkan $\mathrm{A} \in \mathcal{F}_{m n} \mathrm{~A}$ adalah matriks fuzzy regular.

$(\Rightarrow)$ Misalkan $R(B) \subseteq R(A)$. Akan dibuktikan $B=B A^{-} A$.

Karena A matriks fuzzy regular maka $A=A A^{-} A$ dan $R(B) \subseteq R(A)$ maka berdasarkan Proposisi 2.4.1, diperoleh $B=X A$.

$(\Leftarrow) A^{-} \in A\{1\}, A\{1\}$ adalah himpunan dari semua g-invers dari A yang memnuhi $A A^{-} A$. Akan dibuktikan $R(B) \subseteq R(A)$ yakni dengan membuktikan $B=X A$ untuk suatu $X \in \mathcal{F}_{m}$ (berdasarkan Proposisi 2.4.1).

(b) Misalkan $\mathrm{A} \in \mathcal{F}_{m n}$ dan A matriks fuzzy regular.

$(\Rightarrow)$ Misalkan $C(B) \subseteq C(A)$. Akan dibuktikan $B=A A^{-} B$. Karena A adalah matriks fuzzy regular maka $A=A A^{-} A$ dan $C(B) \subseteq C(A)$ maka berdasarkan Proposisi 2.4.1 diperoleh $B=A Y$.

$(\Leftarrow) A^{-} \in \mathrm{A}\{1\}, A\{1\}$ adalah himpunan dari semua g-invers dari A yang memnuhi $A A^{-} A$. Akan dibuktikan $C(B) \subseteq C(A)$ yakni dengan membuktikan $B=A Y$ untuk suatu $X \in \mathcal{F}_{n}$ (berdasarkan Proposisi 2.4.1).

Teorema 4.3. [1] Misalkan $A \in \mathcal{F}_{m n}$ adalah matriks fuzzy regular, $X$ adalah g-invers dari $A$ dan $\lambda \in \mathcal{F}=[0,1]$, maka:

(1) $X^{T} \in A^{T}\{1\}$.

(2) $\lambda X \in(\lambda A)\{1\}$.

(3) $X A$ dan $A X$ adalah idempoten, $R(A)=R(X A)$ dan $C(A)=C(A X)$.

\section{Bukti.}

(1) Misalkan $\mathrm{A} \in \mathcal{F}_{m n}$ adalah matriks fuzzy regular dan $\mathrm{X}$ adalah g-invers dari A. Karena $\mathrm{X}$ adalah g-invers dari A, maka $\mathrm{X}$ memenuhi $A X A=A$. Akan dibuktikan $X^{T} \in A^{T}\{1\} . A^{T}\{1\}$ adalah himpunan dari semua g-invers dari $A^{T}$ yang memenuhi $A^{T} X^{T} A^{T}=A^{T}$. Perhatikan bahwa:

$$
\begin{aligned}
A X A & =A \\
(A X A)^{T} & =A^{T} \\
A^{T} X^{T} A^{T} & =A^{T}
\end{aligned}
$$

(a) Misalkan $\mathrm{A} \in \mathcal{F}_{m n}$ adalah matriks fuzzy regular dan $\lambda X \in(\lambda A)\{1\}$. Akan dibuktikan $(\lambda X) \in(\lambda A)\{1\} .(\lambda A)\{1\}$ adalah himpunan dari semua g-invers dari $(\lambda A)$ yang memenuhi $(\lambda A)(\lambda X)(\lambda A)=\lambda A$.

Misalkan $A=\left(a_{i j}\right)$ dan $\lambda \in \mathcal{F}=[0,1]$. Karena $\lambda A=\left(\min \left(\lambda, a_{i j}\right)\right)=A \lambda$ dan $\lambda \lambda=\min (\lambda \lambda)=\lambda$, maka:

$$
\begin{aligned}
(\lambda A)(\lambda X)(\lambda A) & =(A \lambda)(\lambda X)(\lambda A) \\
& =(A \lambda) X(\lambda A) \\
& =(\lambda A) X(A \lambda) \\
& =\lambda(A \lambda) \\
& =\lambda(\lambda A) \\
& =\lambda A .
\end{aligned}
$$


(b) Akan ditunjukan AX dan XA idempoten.

Perhatikan bahwa:

$$
\begin{aligned}
(A X)^{2} & =(A X)(A X) \\
& =A X
\end{aligned}
$$

dan

$$
\begin{aligned}
(X A)^{2} & =(X A)(X A) \\
& =X A
\end{aligned}
$$

sehingga diperoleh AX dan XA adalah idempoten.

Selanjutnya akan ditunjukan $\mathrm{R}(\mathrm{A})=\mathrm{R}(\mathrm{XA})$ dan $\mathrm{C}(\mathrm{A})=\mathrm{C}(\mathrm{AX})$. Karena $A \in$ $\mathcal{F}_{m n}$ adalah matriks fuzzy regular dan $\mathrm{X}$ adalah g-invers dari $\mathrm{A}$, maka

$\mathrm{A}=$ AXA. Sehingga $\mathrm{R}(\mathrm{AXA})=\mathrm{R}(\mathrm{XA})$, akan ditunjukan $\mathrm{R}(\mathrm{A})=\mathrm{R}(\mathrm{XA})$ yaini dengan menunjukan $\mathrm{R}(\mathrm{AXA})=\mathrm{R}(\mathrm{XA})$. Perhatikan bahwa:

$$
A X A=A(X A)
$$

maka diperoleh $\mathrm{R}(\mathrm{AXA}) \subseteq \mathrm{R}(\mathrm{XA})$. Dan karena

$$
X A=X(A X A)
$$

maka diperoleh $\mathrm{R}(\mathrm{XA}) \subseteq \mathrm{R}(\mathrm{AXA})$.

Dari persamaan (4.1) dan persamaan (4.2) diperoleh $\mathrm{R}(\mathrm{AXA})=\mathrm{R}(\mathrm{XA})$ maka $\mathrm{R}(\mathrm{A})=\mathrm{R}(\mathrm{XA})$.

Teorema 4.4. [1] Untuk matriks fuzzy $A, B$ dengan $R(A)=R(B)$ atau $C(A)=C(B)$ maka $A$ adalah matriks fuzzy regular jika dan hanya jika $B$ adalah matriks fuzzy regular.

Bukti. (i) Misalkan A,B matriks fuzzy, $\mathrm{R}(\mathrm{A})=\mathrm{R}(\mathrm{B})$ (atau $\mathrm{R}(\mathrm{B}) \subseteq \mathrm{R}(\mathrm{A})$ dan $\mathrm{R}(\mathrm{A}) \subseteq \mathrm{R}(\mathrm{B}))$

$(\Rightarrow)$ Misal A adalah matriks fuzzy regular. Akan dibuktikan B adalah matriks fuzzy regular.

Diperoleh $\mathrm{R}(\mathrm{B}) \subseteq \mathrm{R}(\mathrm{A})$ jika dan hanya jika $B=B A^{-} A$.

Selanjutnya, $\mathrm{R}(\mathrm{A}) \subseteq \mathrm{R}(\mathrm{B})$ jika dan hanya jika $A=X B$ untuk suatu $X \in \mathcal{F}_{m}$.

$(\Leftarrow)$ Misal B adalah matriks fuzzy regular. Akan dibuktikan A adalah matriks fuzzy regular.

Diperoleh $\mathrm{R}(\mathrm{A}) \subseteq \mathrm{R}(\mathrm{B})$ jika dan hanya jika $A=A B^{-} B$.

Selanjutnya, $\mathrm{R}(\mathrm{B}) \subseteq \mathrm{R}(\mathrm{A})$ jika dan hanya jika $B=X A$ untuk suatu $X \in \mathcal{F}_{m}$.

$($ ii $)(\Rightarrow)$ Misalkan A,B adalah matriks fuzzy, $\mathrm{C}(\mathrm{A})=\mathrm{C}(\mathrm{B})$ (atau $\mathrm{C}(\mathrm{B}) \subseteq \mathrm{C}(\mathrm{A})$ dan $\mathrm{C}(\mathrm{A}) \subseteq \mathrm{C}(\mathrm{B}))$.

Misal A adalah matriks fuzzy regular. Akan dibuktikan B adalah matriks fuzzy regular.

Diperoleh $\mathrm{C}(\mathrm{B}) \subseteq \mathrm{C}(\mathrm{A})$ jika dan hanya jika $B=A A^{-} B$.

Selanjutnya, $\mathrm{C}(\mathrm{A}) \subseteq \mathrm{C}(\mathrm{B})$ jika dan hanya jika $A=B Y$ untuk suatu $Y \in \mathcal{F}_{n}$. 
$(\Leftarrow)$ Misal B adalah matriks fuzzy regular. Akan ditunjukan A adalah matriks fuzzy regular.

Diperoleh $\mathrm{C}(\mathrm{A}) \subseteq \mathrm{C}(\mathrm{B})$ jika dan hanya jika $A=B B^{-} A$.

Selanjutnya, $\mathrm{C}(\mathrm{B}) \subseteq \mathrm{C}(\mathrm{A})$ jika dan hanya jika $B=A Y$ untuk suatu $Y \in \mathcal{F}_{n}$.

\section{Kesimpulan}

Misal $A, B \in \mathcal{F}_{m n}$

(1) Jika A adalah matriks regular, maka akan berlaku:

(a) $\mathrm{R}(\mathrm{B}) \subseteq \mathrm{R}(\mathrm{A})$ jika dan hanya jika $B=B A^{-} A$ untuk suatu $A^{-} \in \mathrm{A}\{1\}$.

(b) $\mathrm{C}(\mathrm{B}) \subseteq \mathrm{C}(\mathrm{A})$ jika dan hanya jika $B=A A^{-} B$ untuk suatu $A^{-} \in \mathrm{A}\{1\}$.

(2) Jika A adalah matriks regular, $\mathrm{X}$ adalah g-invers dari A dan $\lambda \in \mathcal{F}=[0,1]$, maka:

(a) $X^{T} \in A^{T}\{1\}$.

(b) $\lambda X \in(\lambda A)\{1\}$.

(c) XA dan AX adalah idempoten, $\mathrm{R}(\mathrm{A})=\mathrm{R}(\mathrm{XA})$ dan $\mathrm{C}(\mathrm{A})=\mathrm{C}(\mathrm{AX})$.

(3) Jika $\mathrm{R}(\mathrm{A})=\mathrm{R}(\mathrm{B})$ atau $\mathrm{C}(\mathrm{A})=\mathrm{C}(\mathrm{B})$ maka $\mathrm{A}$ adalah matriks regular jika dan hanya jika $\mathrm{B}$ adalah matriks regular.

\section{Ucapan Terima kasih}

Terima kasih kepada ibu Dr. Yanita, ibu Riri Lestari, M.Si, dan bapak Efendi, M.Si selaku dosen penguji, yang telah memberikan kritik dan saran dalam penulisan makalah ini.

\section{Daftar Pustaka}

[1] Meenakshi, A.R. 2008. Fuzzy Matrix Theory and Applications, MJP Publishers, India.

[2] Shyamal, A.K dan M. Pal. 2004. Two New Operators On Fuzzy Matrices, Journal Application mathematic and Computing. 15: 91 - 107.

[3] Sidky, F.I dan E.G. Enam. 1992. Some Remarks on Section of a Fuzzy Matrix Journal of King Abdulaziz University Science. 4: 145 - 155. 